\title{
Remote Operation of Mining Equipment Using Panoramic Display Systems: Exploring the Sense of Presence
}

\author{
Craig A. James*, Kerstin Haustein, Tomasz P. Bednarz, Leila Alem, Con Caris and \\ Andrew Castleden
}

CSIRO, 1 Technology Court, Pullenvale, QLD, 4069, Australia

\begin{abstract}
The mining industry is interested in tele-operation systems to remove mining operators from hazardous or inconvenient environments while providing them with enough sensory information such that their efficiency is maintained or even enhanced. Similar systems are also used to provide collaboration and assistance in remote problem solving situations, including emergency scenarios. The increased availability of high-speed wired and wireless data networks is promoting the use of immersive environments, but there is not enough evidence yet to support whether such environments significantly improve the field-tested performance of tele-operation systems or not. We are interested in investigating a mixed-presence, tele-operation scenario involving an offsite operator remotely operating a robot as well as an onsite operator co-located with the robot. These scenarios are common in industry, yet poorly researched. We have conducted a trial to explore the effects of immersion on operator spatial awareness, sense of presence and satisfaction, in a mixed presence tele-operation scenario. This paper presents the results of our trial using a panoramic display system that provides some level of immersion. However, unlike virtual environments it provides an immersive view using video of a real remote space. The outcome of our work provides a first step in the exploration of cost effective technologies of potential value to the mining industry.
\end{abstract}

Keywords: Tele-operation, tele-collaboration, remote operation, immersion, panoramic displays, presence, measures, survey and route knowledge.

\section{INTRODUCTION}

In the developed world, surface and underground mining practices have continued to advance over the years, resulting in steady improvements in safety and performance. In the U.S., mining was the single most dangerous industry in 2001, with 23.5 deaths per 100,000 workers [1]. By 2009, this figure had dropped nearly by half to 12.7 deaths per 100,000 workers [2]. As a stark contrast, in developing countries such as China, deaths in the mining industry remain staggeringly high. In 2004, 28 miners died in the US, while 6027 mining-related deaths were recorded in China [3, 4]. Only part of this difference can be attributed to the comparatively larger scale of production in China. The lower rate of death in the U.S. can also be attributed to a higher focus on safety systems and access to improved mining practices and equipment.

However, even with access to better standards and technologies, disaster can still strike. This has been brought into recent focus with the tragic loss of 29 miners at the Pike River incident in New Zealand [5]. Such incidents highlight the dangers inherent to mining where humans are still required to be in close proximity to such repetitive, dangerous and dirty processes.

As part of its Minerals Down Under flagship (MDU), the Commonwealth Science and Industrial Research Organisation (CSIRO) aims to design and evaluate technologies for

*Address correspondence to this author at the CSIRO, 1 Technology Court, Pullenvale, QLD, 4069/CSIRO, Australia;

Tel: +61 73327 4788, +61 457560 578; Fax: +61 73327 4566;

E-mail: craig.a.james@csiro.au tele-operation and tele-collaboration that improve safety and performance in the mining industry [6].

Tele-operation systems extend a person's sensing and manipulation capability to a remote location to control a piece of equipment or a larger process [7, 8]. Telecollaboration systems focus on supporting interactions between geographically distributed individuals or groups to achieve common goals [9].

The challenge shared in both systems is to provide sufficient information to the operator so that the physical separation does not impact on task efficiency. As an added difficulty in the mining industry (or any other industrial environment), operators must be able to maintain this efficiency over an entire shift, on systems that are running 24 hours a day for much of the working year.

Tele-presence, or more simply presence, is the ideal state that an operator can achieve such that the person feels physically present at the remote site $[7,8]$. Interactions with tele-presence systems can be described in terms of immersion, both physical (or sensory) and mental [10]. Sherman et al. in [10] also links mental immersion, or the state of being deeply engaged as having a sense of presence within an environment.

The goal of immersion is the ability to mislead one's senses so as to reinforce the illusion of being somewhere other than one's physical location [11]. In the case of a large flat-screen LCD or a 4-metre, hemispherical dome the presence is defined as perceptual illusion of non-mediation. This occurs when the user fails to perceive the existence of a medium and reacts as if the medium were not there. The 
most common method of measuring presence is postexperimental report based on questionnaries.

The degree of presence experienced by the user may influence the users' task performance. In order to achieve a high-level of presence, user interactions with such systems should be natural, efficient and appropriate to the task goals [12].

Sacau et al. [13] reviewed the role of individual factors in presence. According to them if presence is a subjective mental phenomenon, psychological factors must have an important role on it. Their review showed that, even though many authors claim about the need for a better understanding about this relation, empirical evidence is still very limited.

A number of studies have established that the greater spatial presence in highly immersive environments such as a Cave system does translate in quantifiable improvement in user performance [14], when compared with desktop display and lower immersive system such as HMD (Head Mounted Display). Gruchalla [15] compared a CAVE with a desktop for an oil well path planning application, Arns et al. [14] compared a CAVE with a desktop for the statistical visualisation tool, and the two studies report the superiority of the CAVE system.

Other studies explored the benefits of one particular media. Arthur explored the effects of field of view in a HMD [16] and Barfield et al. [17] reports on the effects of head tracking and stereoscopy on spatial understanding.

All of these studies have compared the performance of these environments using generated virtual worlds as opposed to a video view of the real world.

Alem's [18] work shows how tele-collaboration systems that create video mediated spaces induce a sense of presence. Alem investigates the sense of physical presence a specialist doctor experiences when engaged in a remote consultation a video based tele-health system. The sense of co-presence is also investigated in the context of a video based collaboration system in which users are jointly building a piece of lego toy.

While Cave systems are effective, they are also very costly to deploy. Industry is seeking efficient and cost effective solutions. One promising technology is panoramic display systems as they provide a large field of view and some level of immersion at a much lower cost than a CAVE.

In this paper we investigate the value of a panoramic display system in supporting a mixed presence tele-operation scenario. These scenarios involve an offsite operator remotely operating a robot as well as an onsite operator colocated with the robot. These mixed presence tele-operation scenarios are common in industry, yet poorly researched. We present in this paper the trial we have conducted to explore the effects a panoramic display system has on operator spatial awareness, sense of presence and satisfaction, in a mixed presence tele-operation scenario.

\section{RESEARCH OBJECTIVE AND RESEARCH QUESTIONS}

Our research question is whether there are any tangible benefits to the use of a panoramic display over using a flat-screen display in a mixed presence tele-operation scenario. Would an offsite operator be able to better determine where the robot is in relation to the remote site on a panoramic display? Would a panoramic display system provide users with better depth cues to help them build a better spatial awareness? Would an offsite operator feel more present in the remote location using a panoramic display?

In conducting this trial, we hypothesised the following:

Hypothesis 1: Spatial awareness scores of offsite operators will be higher in the panoramic dome display condition than in the flat LCD screen display condition. This should be reflected in path memory.

Hypothesis 2: Subjective measures of presence will be higher for the panoramic dome display condition than in the flat LCD screen display condition. This should be reflected in scores for the question "I felt that my partner and I were at the same location",

\section{EXPERIMENTAL SETUP}

The present experiments were carried out at the CSIRO's Queensland Centre for Advanced Technologies (QCAT) in Brisbane, Australia. The investigations concerned remote collaboration scenarios. Therefore the experiment was carried out mutually in two different locations (a) an on-site and (b) an off-site location.

\section{On-Site Location}

A remotely controlled vehicle called the Phoenix was deployed for the on-site component, and was situated outdoors in the QCAT grounds. The Phoenix is a skid-steer unmanned ground vehicle that was originally designed to convey information on the condition of underground mines during hazardous situations (then known as the Numbat). In our case, it was used to assist an operator performing a task out in the field (please refer to the next section for task details). The Numbat was developed in the early 1990's by CSIRO following the Moura mine explosion in 1986 and it has a long and illustrious career of mine exploration and as a platform for sensor technology and algorithm development $[19,20]$. The Phoenix, as shown in Fig. (1), is an eightwheeled vehicle with a base measuring $2.5 \times 1.65$ metres. It was designed to traverse through terrain and operate in extremely harsh underground mining environments. Pairs of Phoenix wheels mounted on rocker arms move independently over rough surfaces. Vehicle skid-steering (and hence, direction control) is achieved by differential speed control of the left and right wheel sets. This configuration serves to keep all wheels on the ground while the vehicle is traversing rough terrain. The vehicle is designed so that it can propel itself across shallow water obstacles and flooded roadways. The Phoenix can be controlled in two different ways: autonomously by the onboard computer system, or by a wireless remote control. From a safety perspective, the Phoenix also has installed collision sensors, emergency shut-off buttons and warning lights. Additionally, multiple sensors are installed on the platform including differential GPS, Inertial Measurement Unit (IMU), Doppler radar, laser rangefinders, the centrally mounted Ladybug $3 \AA 360^{\circ}$ spherical digital video camera to provide panoramic vision and other equipment. 


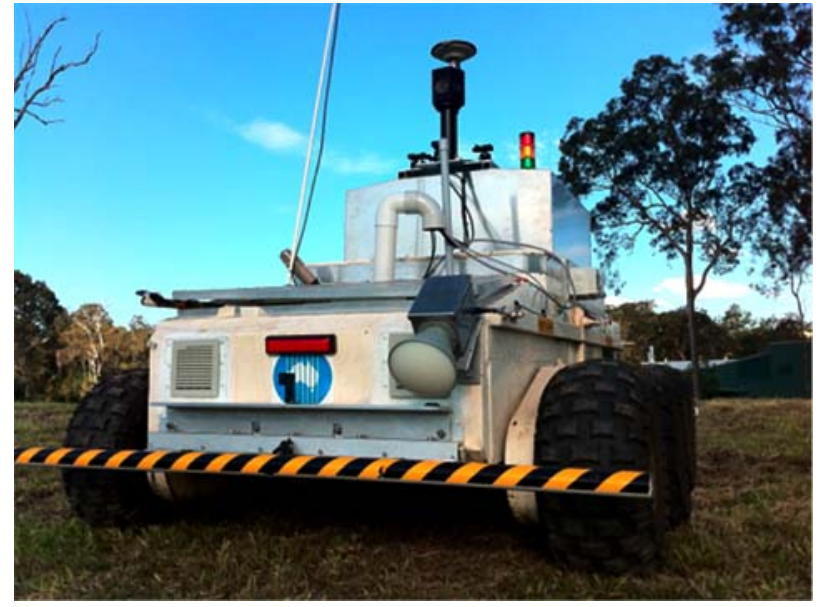

Fig. (1). The Phoenix unmanned ground vehicle.

For the experiment, a secondary channel was added to the Phoenix that allowed the off-site and on-site operators involved in the trial to share control over separate, wireless controllers. The on-site operator also had access to a wireless headset to provide two-way audio communications.

\section{Off-Site Location}

The off-site component was conducted in the Virtual Mining Centre laboratory (VMC). The VMC is set up to allow experiments with various visual, aural, control and haptic devices with a focus on applications in the resources sector. For the current experiments, the VMC was set up to compare flat screen and panoramic display conditions:

- The LCD condition is shown in Fig. (2) with the offsite operator seated at a standard computer desk using a 30" flat LCD display providing an 80-degree viewing angle.

- The Dome condition is shown in Fig. (3) with the offsite operator seated at the focus of a four-metre dome using a rear-projection system, providing a panoramic,180-degree viewing angle.

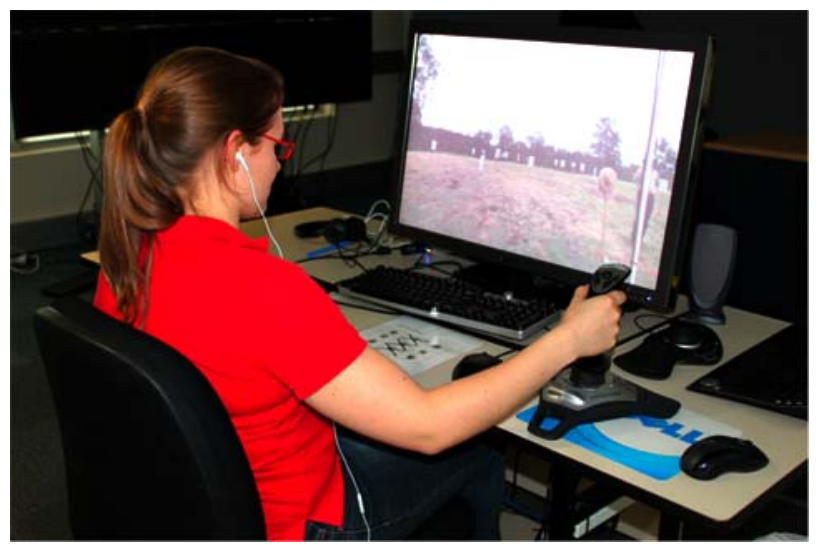

Fig. (2). An off-site operator using the LCD screen display.

Both conditions displayed a HD video signal to the user at a resolution of $1920 \times 1080$ pixels.

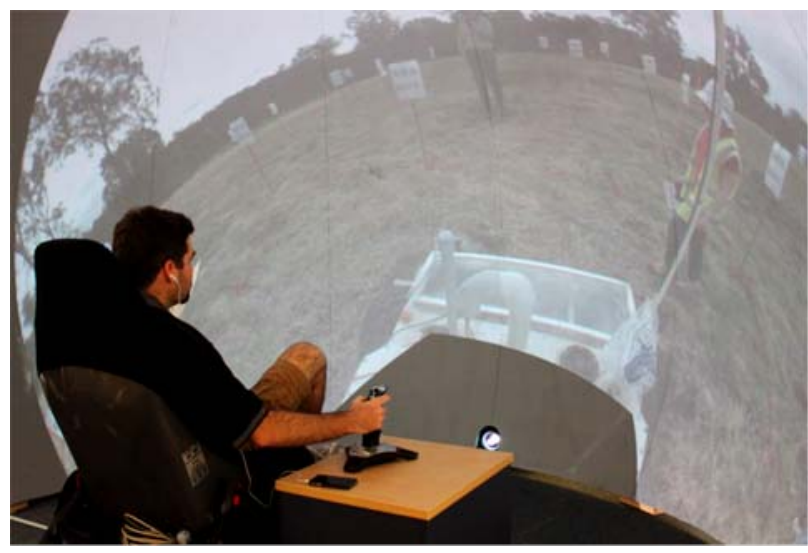

Fig. (3). An off-site operator using the dome display.

\section{Communication and Control}

For the experiment, the Phoenix used a wireless $\mathrm{N}$ receiver to link to an access point situated on-site. The wireless access point was then routed to the VMC over an internal gigabit network. The dual-band wireless link had an ideal maximum throughput of $300 \mathrm{Mbps}$, however measurements on the day averaged $100 \mathrm{Mbps}$ with short periods dropping to under $5 \mathrm{Mbps}$. The line-of-sight range was limited to around 50 metres, which was sufficient for the experiment.

In addition to the one-way video transmitted to the VMC (using a custom TCP protocol), the network link also carried an audio signal from an external microphone mounted on the Phoenix and voice-over-ip (VOIP) between the operators. The network link also relayed signals from the off-site operator in the VMC to control both the movement of the Phoenix and the virtual point-of-view from the Ladybug camera.

The on-site operator also carried a wireless gamepad that could control the motors on the Phoenix. Control signals from the off-site and on-site operators were mixed together allowing cooperative (or contentious) control of the Phoenix.

After capture and compression, video was transmitted at up to 12 frames per second (the Ladybug camera is limited to a maximum of $15 \mathrm{fps}$ ). Filtering on the control signals also introduced up to $300 \mathrm{~ms}$ latency to prevent damage to the Phoenix motors from rapid direction changes.

\section{Task}

A task was designed to force both operators to collaborate to complete successfully. In this experiment the task involved moving the Phoenix through a maze that required knowledge from both operators to navigate successfully.

The maze consisted of a $3 \times 3$ matrix each cell measuring $5 \times 5$ meters. There were no walls but the boundary of each cell was marked with lines painted on the ground. The lines were positioned on the ground to make it harder for the offsite operator to see, necessitating feedback from the on-site operator to prevent imagined 'collisions' with the walls. In a further effort to encourage collaboration, the on-site operator 
was shown marks between each cell that the Phoenix was required to pass between. These marks were also positioned out of the off-site operator's view, leaving it up to the on-site operator to ensure that the Phoenix passed through without any unplanned wall 'collisions'. Fig. (4) shows the Phoenix and an on-site operator negotiating the maze.

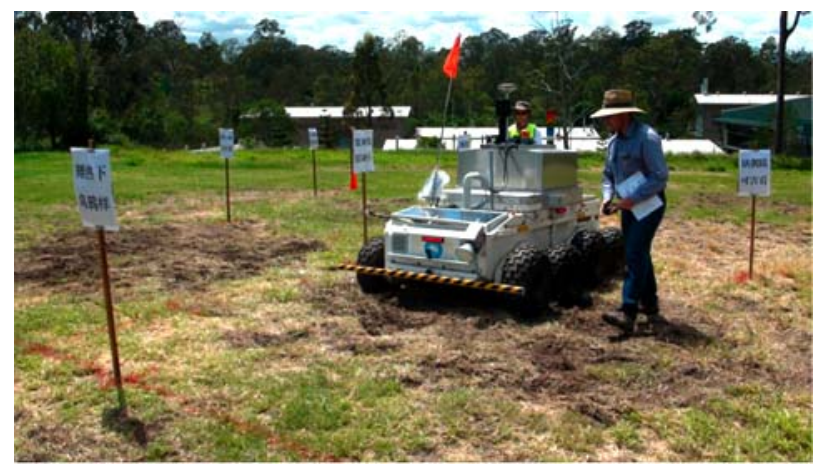

Fig. (4). An on-site operator, in the maze, with the Phoenix.

At the boundary of each cell, a sign with 6 unfamiliar symbols acted as a gate that blocked the way forward. At the start of each pass through the maze, on-site and off-site operators were given separate sheets of permitted symbols. In order to pass any gate, both operators had to find a matching symbol on their respective sheets. Fig. (5) shows the overall layout of the maze and Fig. (6) shows an example of on-site and off-site operators picking matching symbols to pass a gate.

The Chinese character set was chosen for the symbols. Our participants were not familiar with Chinese characters; this made a verbal description of the symbols difficult and encouraged the participants to rely on the remote visual (video) component of the collaborative environment for the purpose of comparing the 2 types of screens. The sheer number of characters helped prevent memory retention for a particular participant between conditions.

Each path was pre-determined and took operators into four cells before exiting the maze. Either operator could take control the Phoenix at any time and this was left to the operators to negotiate who had control at a given time. Operators could communicate freely with each other during the task but were discouraged from showing each other their sheets, interfering with the maze (eg moving signs to better viewing conditions remotely) or looking ahead at other cells.

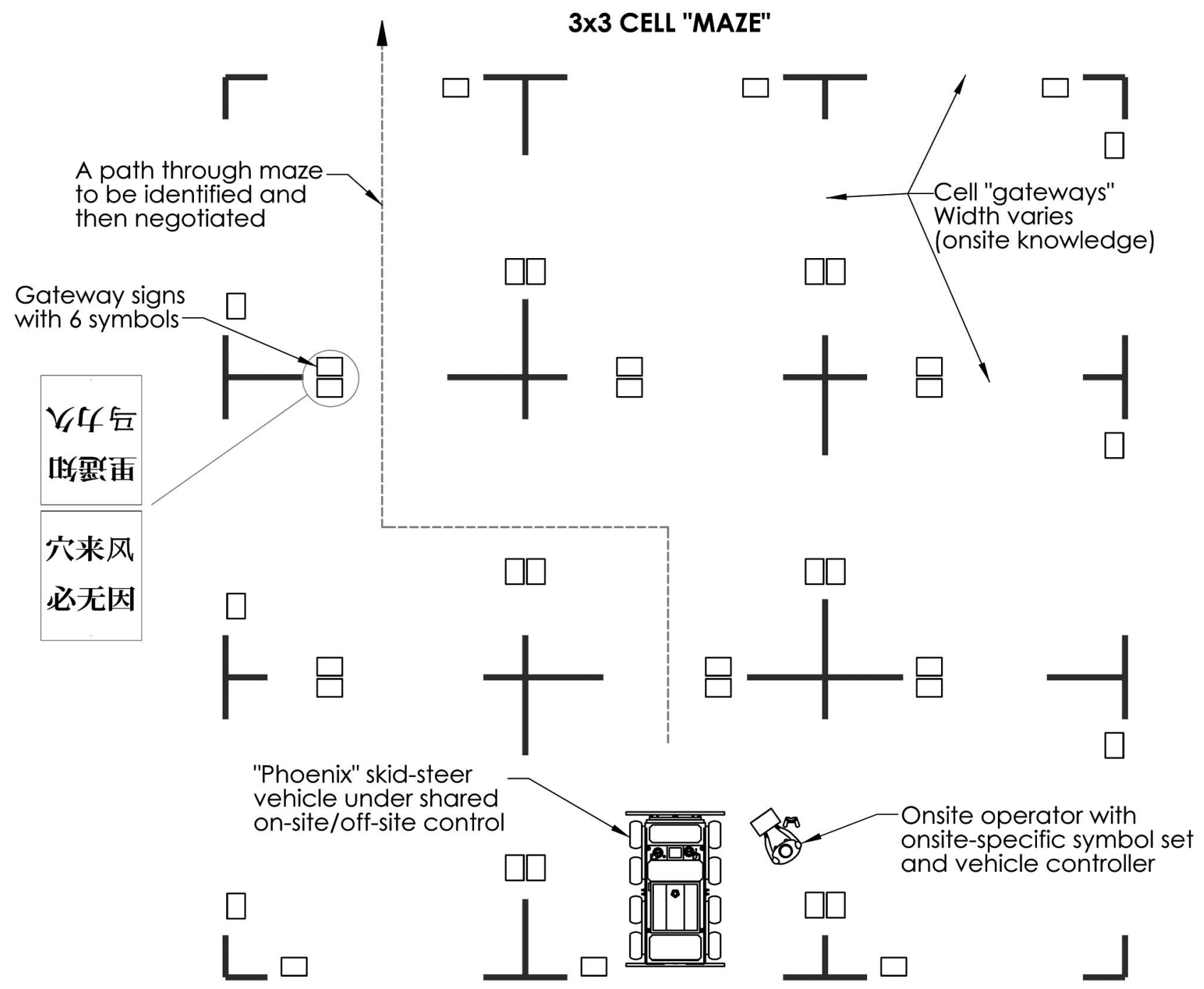

Fig. (5). On-site maze showing pre-determined path. 


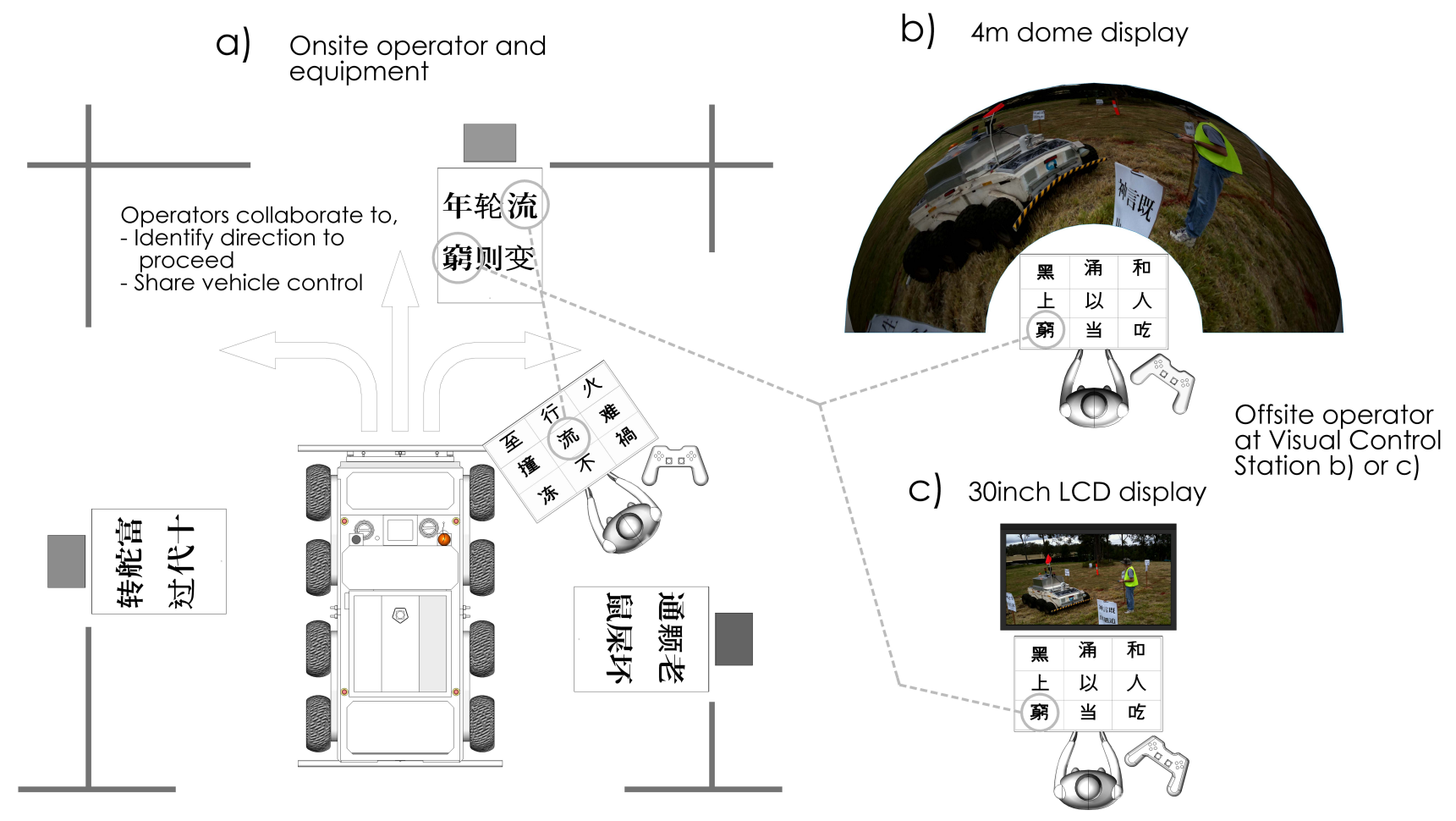

Fig. (6). a) On-site operator; b) Off-site operator with dome display; c) Off-site operator with LCD.

The task could be reset quickly and repeated with a different path by using a different set of sheets provided to the operators. The same paths were used in the same order for each pair of participants for task execution comparison.

\section{Measures}

Kaber and $\mathrm{Ma}$ in [21] review measures of presence, splitting between subjective (survey-based) and objective (quantitative) measures. Reference is also given to the differences in system, task and environmental factors that make it difficult to assign a single index across different experiences of presence [22]. This difficulty is not a factor in our experiment as it aims for a repeatable experience across different immersion conditions.

Several objective and subjective measures were used to collect data from participants after each trial in our experiment. Physiological measures such as heart rate and skin conductance were also considered but have not been shown to be broadly applicable across cognitive measures to date [23].

Lee et al. [8] and Payne et al. [24] use survey and route knowledge as objective measures of spatial awareness, which in itself is a measure of presence. After each trial in our study, participants were given a survey knowledge test by asking them to identify symbols that marked the correct path. This was followed by a route knowledge test that asked participants to mark down the correct path taken on a map of the maze. The objective measures also included recording overall time to complete the course.

The subjective measures included a general questionnaire shown in Fig. (11), which asked questions on satisfaction and comfort drawn from [25]. This covered the participants' comfort, satisfaction, awareness, system usability and sense of control. Participants were also asked to complete the NASA Task Index [26], which is a widely accepted measure of cognitive load, and a system usability questionnaire [27].

Both on-site and off-site trials were also videotaped for later review.

\section{EXPERIMENTAL PROCEDURE}

Ten people participated in the experiment, and were split into five teams. Technical backgrounds and gender biases were not investigated in this experiment and so the participants were drawn randomly from a mix of backgrounds and gender. For this smaller scale trial, participants were sourced from CSIRO and all gave their verbal consent to join in the exercises. In addition to the participants, there were two experimentalists on-site (supervisor and video recorder) and two off-site (supervisor and survey taker).

Each team performed four runs through the maze. One such run is shown in Fig. (4). Each person took the part of being the off-site operator using LCD and dome displays in separate runs. The order of which display was used first was counterbalanced across the teams in order to reduce bias. Operators were given a route and symbol memory test at the end of each run, before resetting the experiment for the next one. At the end of all four runs, both members of the team were interviewed and given the survey forms to complete.

There was approximately a half-day of set up to prepare the maze and a half-day at the end to close it down. Preexisting software and hardware from the VMC lab was 
utilised where possible and some development time was spent adding a shared remote control and an audio link. Another half-day was spent manufacturing the necessary signs, instructions and surveys but this work can be re-used in follow-up experiments.

\section{RESULTS}

The experiment took three days to complete. This does not include an additional day to set up and shut down nor does it include a day in the middle lost through inclement weather.

The setup for the experiment generally performed well but there were some problems. Networking infrastructure issues caused a delayed start on the first morning. There were also wireless dropouts that slowed the video frame-rate on occasion, forcing a system resets in between trials.

Heavy use of the Phoenix on the first day ran the battery charge down to a point meaning we had to abandon one of the runs for the last team on that day. We also rejected one of the runs as, after examining the videos, we realised one onsite operator was looking ahead to match symbols in other cells while the offsite operator was occupied with the signs in the current cell.

Results were calculated for each experimental condition, comparing mean scores for the LCD and Dome conditions, and offsite and onsite conditions for each objective and subjective test. The results were then analysed by way of a two-way analysis of variance score (ANOVA) for all conditions other than the time to complete each trial, which was analysed using a one-way ANOVA.

A summary of results (mean for each Dome/LCD Screen and Off-site/On-site condition and the significance scores for that result) is tabled in Fig. (7). Graphs are shown for the Symbol Memory test in Fig. (8), Path Memory test in Fig. (9), Task Completion Times in Fig. (10), General Questionnaire (see Fig. 11) ratings in Fig. (12), the NASA Task Index in Fig. (13), and the System Usability Question in Fig. (14).

Results were considered statistically significant where $\mathrm{P}$ $<0.05$, that is, the probability that the differences in the means could have occurred by chance was less than 1 in 20 .

For the Symbol Memory Test, the mean score was slightly higher for participants using the LCD screen $(3.33$ out of 4 ) than the dome screen (3.25 out of 4$), P=0.763$, however for the Path Memory Test, the mean score was higher for participants using the dome (3.93 out of 4 ) than the LCD screen (3.73 out of 4$), P=0.703$.

For the scale given as part of General Questionnaire, questions were answered on a 1 to 7 scale (strongly disagree to strongly agree). For the co-presence measure, "I felt that my partner and I were at the same location", the mean score was higher for participants using the LCD screen (4.70, agree) than the Dome (4.44, neutral), $\mathrm{P}=0.340$.

The participants were also given the opportunity to provide written feedback about their experience with the system, and several similar comments arose.

- 6 of the 10 participants commented that there was a problem with the image clarity with the dome.

- 5 of the 10 participants suggested that a persistent camera pan would have been preferable to a camera pan that defaulted back to origin upon joystick release.

- 2 participants commented that there was a problem

\begin{tabular}{|c|c|c|c|c|c|c|}
\hline Measure & $\begin{array}{l}\text { Dome } \\
(\mu)\end{array}$ & $\begin{array}{l}\text { LCD Screen } \\
(\mu)\end{array}$ & $\begin{array}{l}\text { Screen } \\
\text { (P) }\end{array}$ & $\begin{array}{l}\text { Off-site } \\
(\mu)\end{array}$ & $\begin{array}{l}\text { On-site } \\
(\mu)\end{array}$ & $\begin{array}{l}\text { Location } \\
\text { (P) }\end{array}$ \\
\hline Symbol Memory Test & 3.25 & 3.33 & .763 & 3.46 & 3.13 & .232 \\
\hline Path Memory Test & 3.93 & 3.73 & .703 & 3.59 & 3.95 & .112 \\
\hline Time to Complete & $12: 54 \mathrm{~min}$ & $15: 30 \mathrm{~min}$ & .320 & $\mathrm{n} / \mathrm{a}$ & $\mathrm{n} / \mathrm{a}$ & $\mathrm{n} / \mathrm{a}$ \\
\hline I felt the system is easy to learn & $5.56(\mathrm{~A})$ & $\begin{array}{l}5.45 \\
\text { (A) }\end{array}$ & .708 & $\begin{array}{l}5.11 \\
\text { (A) }\end{array}$ & $\begin{array}{l}5.89 \\
\text { (A) }\end{array}$ & .015 \\
\hline I felt the system is easy to use & $\begin{array}{l}5.37 \\
\text { (A) }\end{array}$ & $\begin{array}{l}5.25 \\
\text { (A) }\end{array}$ & .717 & $\begin{array}{l}4.83 \\
\text { (A) }\end{array}$ & $\begin{array}{l}5.78 \\
\text { (A) }\end{array}$ & .011 \\
\hline I am satisfied with my task performance & $\begin{array}{l}3.88 \\
(\mathrm{~N})\end{array}$ & $\begin{array}{l}4.3 \\
(\mathrm{~N})\end{array}$ & .396 & $\begin{array}{l}4.11 \\
(\mathrm{~N})\end{array}$ & $\begin{array}{l}4.11 \\
(\mathrm{~N})\end{array}$ & .960 \\
\hline I felt that my partner and I were at the same location & $\begin{array}{l}4.44 \\
(\mathrm{~N})\end{array}$ & $\begin{array}{l}4.75 \\
\text { (A) }\end{array}$ & .340 & $\begin{array}{l}4.67 \\
\text { (A) }\end{array}$ & $\begin{array}{l}4.56 \\
\text { (A) }\end{array}$ & .729 \\
\hline I am satisfied with the interaction with my partner & $\begin{array}{l}5.00 \\
\text { (A) }\end{array}$ & $\begin{array}{l}5.10 \\
\text { (A) }\end{array}$ & .784 & $\begin{array}{l}4.94 \\
\text { (A) }\end{array}$ & $\begin{array}{l}5.17 \\
\text { (A) }\end{array}$ & .539 \\
\hline I felt that the process of communication between partner and me is smooth & $\begin{array}{l}5.44 \\
\text { (A) }\end{array}$ & $\begin{array}{l}5.45 \\
\text { (A) }\end{array}$ & .965 & $\begin{array}{l}5.39 \\
\text { (A) }\end{array}$ & $\begin{array}{l}5.50 \\
\text { (A) }\end{array}$ & .694 \\
\hline NASA Task Index & 52.88 & 48.00 & .331 & 45.78 & 54.56 & .071 \\
\hline System Usability Scale & 72.33 & 75.13 & .344 & 72.35 & 75.42 & .304 \\
\hline
\end{tabular}

Fig. (7). The means and probabilities for each measure for the Screen and Location conditions. 
with image clarity with the LCD screen.

- 2 of the participants that commented on the poor image clarity of the dome suggesting that the image was clearer on the LCD screen.

- 1 participant commented that the contrast on the LCD screen was better but that the LCD did not give as wide a view of the surroundings as the dome.

- 2 participants commented that a miniature map on the screen for the off-site operator would have been useful to help understand where the Phoenix was in relation to the maze,

- 2 participants commented that a camera zoom function for the offsite operator would have been useful.

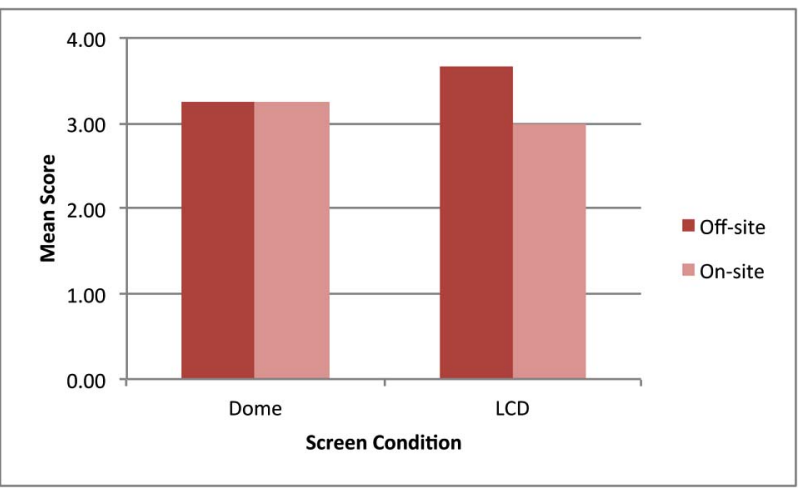

Fig. (8). Symbol Memory Test scores for each Screen $(\mathrm{P}=0.763)$ and Location $(\mathrm{P}=0.232)$ condition.

\section{DISCUSSION AND CONCLUSIONS}

The results for the Path Memory test showed better path recognition for the dome condition than the LCD screen condition. While this score was not significant, likely due to the low range of possible test scores $(0,1,2,3,4)$, it suggests that spatial awareness may have been greater using the dome to interact with the collaborative environment than the flat LCD screen, as per our hypothesis. This was also a comment made by one participant in the written feedback. Greater spatial awareness was expected with the dome because the technology shows a greater correspondence between the image displayed and its source direction, giving the user a greater perception of direction in general, compulsory for spatial awareness. Spatial awareness and the subjective experience of physical presence in the remote location are important factors in tele-operation, tele-assistance and telecollaboration applications in mining scenarios. In future work, we would like to further investigate the relation between spatial awareness and physical presence.

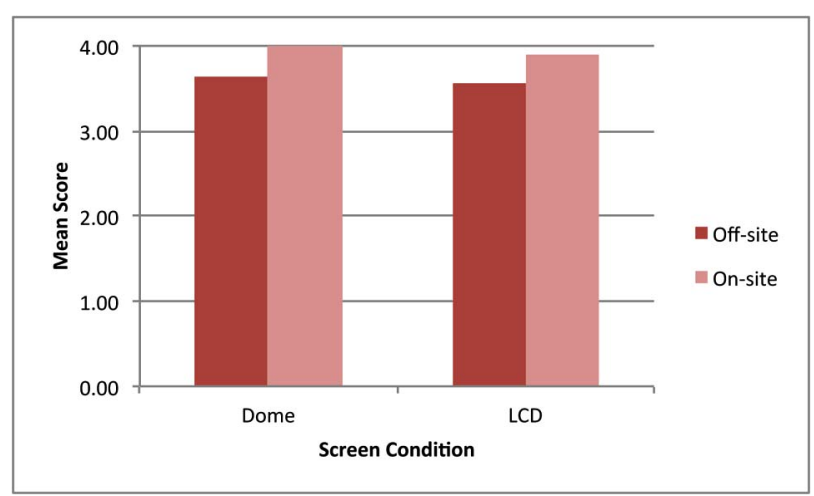

Fig. (9). Path Memory Test scores for each Screen $(P=0.703)$ and Location $(\mathrm{P}=0.112)$ condition.

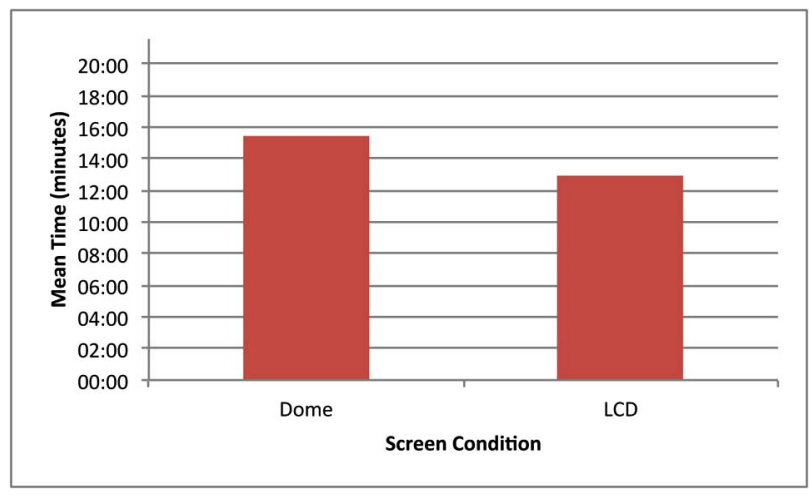

Fig. (10). Task Completion times for each Screen condition $(\mathrm{P}=$ $0.320)$.

The results for the Symbol Memory test showed better symbol recognition for the flat LCD screen condition than

Design and evaluation of user interfaces for remote collaborative augmented reality

Indicate your preferred answer by (marking an " $\mathrm{X}$ " in the appropriate box of the seven-point scale. Please consider the entire scale when making your responses.

\begin{tabular}{|l|l|l|l|l|l|l|l|}
\hline & & Strongly disagree & & \multicolumn{2}{l|}{ Strongly agree } \\
\hline & Question & 1 & 2 & 3 & 4 & 5 & 6 \\
\hline 1 & I felt the system is easy to learn & & & & & 7 & \\
\hline 2 & I felt the system is easy to use & & & & & & \\
\hline 3 & I am satisfied with my task performance & & & & & & \\
\hline 4 & I felt that my partner and I were at the same location & & & & & & \\
\hline 5 & I am satisfied with the interaction with my partner & & & & & & \\
\hline 6 & $\begin{array}{l}\text { I felt that the process of communication between } \\
\text { partner and me is smooth }\end{array}$ & & & & & & \\
\hline
\end{tabular}

Fig. (11). The rating scale given in the General Questionnaire that was given to participants for each experimental condition; only the results for the Location (Offsite/Onsite) condition for Question 1 and 2 were found to be statistically significant $(\mathrm{P}=0.015)$. 
the dome condition. This score was not significant, possibly due to a low range of possible test scores $(0,1,2,3,4)$ and conflicts with the proposed hypothesis, that symbol memory would be better for the dome condition than for the LCD condition. Good symbol recognition would be desirable, as better symbol recognition would indicate a more precise visual perception. One likely explanation of our results is the image quality issue experienced by our participants in the dome condition the symbol appeared clearer on the LCD screen than the dome, as indicated by participant feedback. As the participants could not view the symbol as clearly, it was harder to recognise when printed clearly on the memory test. This suggests that symbol recognition can be increased when improving the image quality of the dome.

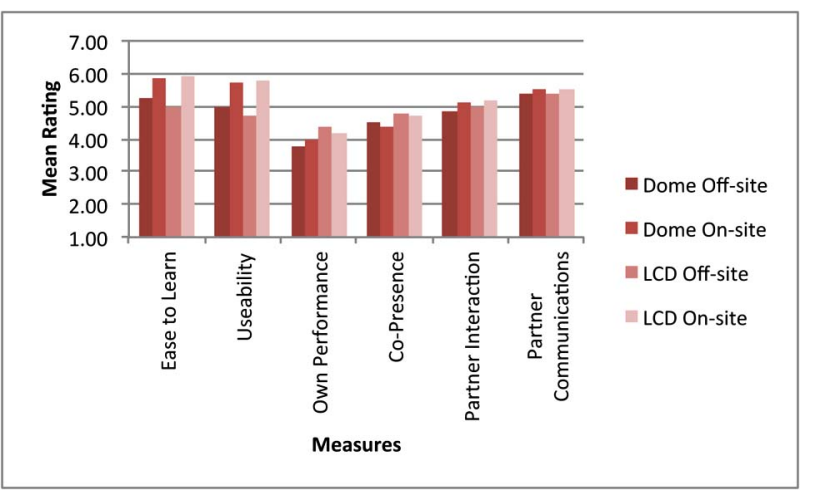

Fig. (12). General Questionnaire ratings for each experimental condition.

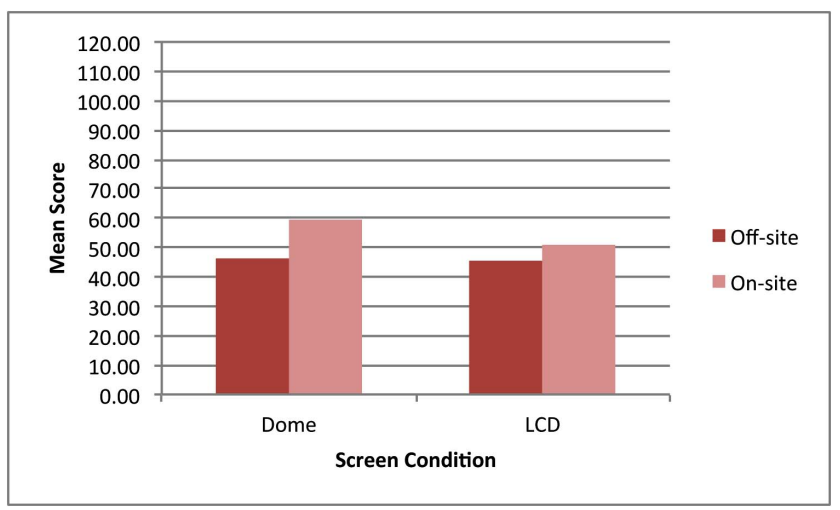

Fig. (13). Measures of cognitive load using the NASA Task Index for each Screen $(\mathrm{P}=0.331)$ and Location $(\mathrm{P}=0.071)$ condition.

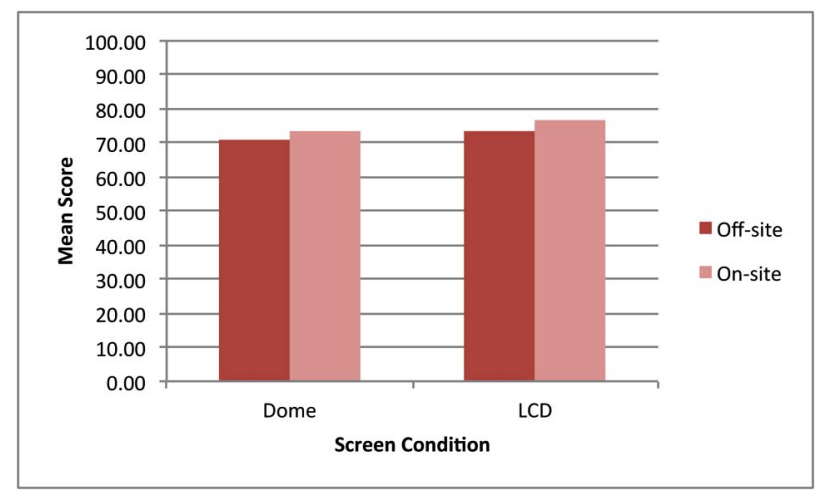

Fig. (14). Scores on the System Usability Scale for each Screen (P $=0.344)$ and Location $(\mathrm{P}=0.304)$ condition.
The greater path memory but decreased symbol memory using the dome may be an indicator that the dome acts more as an awareness system than an immersive system in this application.

The dome condition was rated as easier to use and learn by participants than the flat LCD screen condition. These results were not significant, however it may indicate an advantage to using a dome-based display for telecollaborative systems.

The dome condition scored lower than the flat LCD screen condition in the co-presence measure. While this result was not statistically significant it suggests that the dome did not increase the subjective experience of copresence when compared to the LCD screen, contrary to our hypothesis. One possible explanation for such results is that the greater screen clarity of the LCD screen enhanced the off-site participant's view of their partner, and hence their feeling of being in the same room, or co-present.

Due to the expected correlation between high visual perception, recognition and the subjective experience of physical presence, Symbol and Path Memory tests seem to be promising measures of physical presence in telecollaborative environments. They are also useful measures of the accuracy involved with each technology; safety being a primary focus of the mining industry, high levels of accuracy are essential.

When analysing the objective test scores, it was found that many of the results did not display a high level of significance. As noted in the introduction, the number of participants was kept low for this trial and it is expected that the significance of results will increase with more participants. There are also changes to the experimental procedure that can increase significance. Of particular note is that the path matching tests showed the least significance, suggesting that the paths were too short. This decision was made to limit the maze to a $3 \times 3$ matrix to keep set up time low. However this meant the variation of results suffered from only having four steps to score out of. Allowing the path to cross over cells that have been previously visited can increase the number of steps. This can be achieved by giving the operators a sequence of sheets, one for each cell they have to navigate (plus a few more so they don't know when the maze exit is coming up). This also has the added benefit of increasing the variation of the memory test.

Adding variation of path lengths would also increase significance of results. Each display condition will need an equal number of matching path lengths in order to avoid bias. Paths should also be started from the centre of the maze to maximise the number of possible starting options.

In spite of the low-significance of objective scores drawn from the trial, there are several promising trends that can be investigated in a larger scale experiment.

It appears that there is better symbol recognition off-site than on-site. This seems counter-intuitive as it suggests that one of the measures of presence, namely survey knowledge, is improved in the more-limited remote experience. It is more likely however that this resulted from a common behaviour observed in the teams to send the on-site operator around first to match symbols and only bring the off-site 
operator to examine potential candidates. In this way, the off-site operator had less exposure to the wider variety of symbols and could perhaps more easily remember the symbols chosen in the follow-up test. Ensuring that there are at least two matching signs for both on-site and off-site operators can help offset this bias.

The results also suggested that task completion times were quicker when teams used the flat screen display over the panoramic one. This improvement is likely a result of relative clarity between the smaller flat screen LCD and the dome display. As suggested above, a zoom feature would help the performance of both display systems and will likely bring these results closer together.

On the whole, the experimental setup was relatively quick to set up, conduct and dismantle. The low number of participants in the trial produced measured results that are not statistically significant. The trial did succeed in identifying issues in the setup, showed where we can increase significance independent of the number of participants, and highlighted some promising trends that will aid in design of a larger scale experiment.

There are several issues to resolve in the experimental setup before scaling up to a more significant trial.

The first issue is to review and retest the wireless setup. Previous tests in the location did not have any difficulties but the increased length of the trial, local RF conditions inside the Phoenix or external environmental RF conditions may have contributed to problems on the day.

The second issue concerns the failure of the on-site wireless audio headset. This forced the use of mobile phones in the trial and was less convenient and more costly. The failure of this headset may have been due to a device battery issue or local RF conditions.

The third issue comes from feedback that the clarity of the LCD is significantly better than the dome display. This apparent difference is due to the same resolution on the 30 " LCD being stretched across a $4 \mathrm{~m}$ dome. The LCD also focuses the full resolution in an 80-degree field of view, compared to the same resolution stretched across 180degrees for the dome. One suggested solution is to incorporate zoom functionality in the display system. The source image from the Ladybug camera is 12 megapixels but is being transmitted at only 2 megapixel for display in HD resolution (1920x1080). This leaves plenty of resolution available for a digital zoom to be implemented.

The fourth issue comes from feedback comments indicating that the camera view was difficult to control. The initial premise was to have the camera revert back to the forward-facing orientation when the camera control was released in order to preserve a sense of forward-facing direction. In practice, this made it hard to keep the point of view centred on a sign unless the Phoenix was facing it directly - resulting in a lot of unnecessary movement to line the vehicle up with the signs. This issue can be resolved by modifying the controls to allow relative positioning (much like using a mouse), while having a manual reset to realign the camera as needed.

Possibilities for future work, along with improving on the current experiment, include a comparison between the two different types of presence (physical presence and copresence), how these are related to the spatial awareness experienced for Immersive and Non-Immersive environments, and the degree to which the dome may increase the level of Immersion relative to a standard LCD flat screen. While presence has been the focus of this paper, other important aspects of user's performance and experience could be investigated. Aspects such as safety, collaboration and comfort, along with various miningspecific factors, could be investigated while exploring the ideal tele-collaborative environment for the mining industry.

\section{ACKNOWLEDGEMENTS}

The authors would like to acknowledge the time and effort invested for all experiment participants, in no particular order: Jeremy Thompson, Chad Hargrave, Dr Mark Dunn, Peter Wang, Lance Munday, Stuart Addinell, Dr Eleonora Widzyk-Capehart, Catherine Hayward, Kellie Muffatti, and Peter Reid.

\section{CONFLICT OF INTEREST}

None declared.

\section{REFERENCES}

[1] Bocco D. Is Mining Dangerous? Retrieved from the wiseGEEK website; [2010 October 30] available from: http://www.wisegeek. com/is-mining-dangerous.htm

[2] U.S. Bureau of Labor Statistics. Census of Fatal Occupational Injuries Charts, 1992-2009. U.S. Department of Labor, 2010. [Retrieved 2010 October 30] available from http://www. bls.gov/iif/oshcfoil.htm

[3] Wikipedia. Coal mining. Retrieved from the Wikipedia website; [2010 October 30] available from: http://en.wikipedia.org/wiki/ Coal_mining\#Safety

[4] China Labour Bulletin. Deconstructing details from China's coal mine safety statistics. Retrieved from the website of the China Labour Bulletin; [2010 October 30] available from: http://www.clb. org.hk/en/node/19316

[5] Wikipedia. Pike River Mine disaster. Retrieved from the Wikipedia website; [2010 November 30] available from: http://en.wikipedia. org/wiki/Pike_River_mine_accident

[6] Commonwealth Science and Industry Research Organisation. The Minerals Down Under National Research Flagship: An Overview for 2010. Canberra, ACT: CSIRO Publishing, 2010 [Retrieved 2010 October 30] available from http://www.csiro.au/science/Trans forming-Future-Mine.html

[7] Sheridan TB. Telerobotics. Automatica 1989; 25(4): 487-507.

[8] Lee S, Kim GJ. Effects of haptic feedback, stereoscopy, and image resolution on performance and presence in remote navigation. Int $\mathrm{J}$ Hum Comput Stud 2008; 66: 701-17.

[9] Abler RT, Wells IG. Distributed engineering education: evolution of the telecollaboration stations for individualized distance learning. IEEE Trans Educ 2005; pp. 490-96. [Retrieved 2010 October 30] available from http://ieeexplore.ieee.org/xpls/abs_all. jsp?arnumber $=1495657$

[10] Sherman WR, Craig AB. Understanding virtual reality: interface, application, and design. Elsevier Science: USA. Morgan Kaufman 2003.

[11] Sylaiou S, Mania K, Karoulis A, White M. Exploring the relationship between presence and enjoyment in virtual museum. Int J Hum Comp Stud 2010; 68: 243-53.

[12] Stanney KM, Mollaghasemi M, Reeves L, Breaux R, Graeber DA. Usability engineering of virtual environments (VEs): identifying multiple criteria that drive effective VE system design. Int J Hum Comp Stud 2003; 58: 447-81.

[13] Sacau A, Laarni J, Hartmann T. Influence of individual factors on presence. Comp Hum Behav 2008; 24: 2255-73.

[14] Arns L, Cook D, Cruz-Neira C. The benefits of statistical visualization in an immersive environment. In: Proceedings of IEEE Virtual Reality 1999; Houston, USA. 
[15] Gruchalla K. Immersive well-path editing: Investigating the added value of immersion. In: Proceedings of IEEE Virtual Reality 2004; Chicago, USA.

[16] Arthur K. Effects of field of view on performance with headmounted displays. PhD [unpublished dissertation], Chapel Hill: University of North Carolina 2000.

[17] Barfield W, Hendrix C, Bystrom K. Visualizing the structure of virtual objects using head tracked stereoscopic displays. In: Proceedings of the Virtual Reality Annual International Symposium 1997; Albuquerque, USA.

[18] Alem L. Presence in video mediated interaction: case studies at CSIRO. Harrison S, Ed. Media space: $20+$ years of mediated Life. Australia, 2009.

[19] Hainsworth DW, Stacey MR. Mine emergency survey vehicle: Numbat. In: Proceedings of International Conference of Safety in Mines Research Institutes 1993; Pretoria, South Africa.

[20] Ralston JC, Hainsworth DW. The Numbat: a remotely controlled mine emergency response vehicle. In: Proceedings of International Conference on Field and Service Robotics 1997; Canberra, Australia.

[21] Ma R, Kaber DB. Presence, workload and performance effects of synthetic environment design factors. Edward P. Fitts Department of Industrial Engineering, North Carolina State University 2006; Raleigh, USA.
[22] Stanney KM, Mourant RR, Kennedy RS. Human factors issues in virtual environments. Presence: Teleoperators Virtual Environ 1998; 7 (4): 327-51.

[23] Curtis S, Ikehara, CS, Crosby ME. Assessing cognitive load with physiological sensors. In: Proceedings of the 38th Hawaii Internatio-nal Conference on System Sciences; 2005. Hawaii, USA. [Retrieved 2010 October 30] available from http://ieeexplore.ieee. org/stamp/stamp.jsp?tp=\&arnumber=1385846\&userType=inst

[24] Payne RA, Payne SJ, Jones DM. Navigating large-scale "desk-top" virtual buildings: effects of orientation aids and familiarity. Presence: Teleoperators Virtual Environ 1998; 7(2): 179-92.

[25] Witmer BG, Singer MJ. Measuring Presence in Virtual Environments: A Presence Questionnaire. U.S. Presence 1998; 7 (3): 225-40.

[26] Tracy JP, Albers MJ. Measuring Cognitive Load to Test the Usability of Web Sites. Usability and Information Design, 2006; pp 256-260. [Retrieved 2010 November 23] available from http:// www.stcsig.org/sn/PDF/Tracy measuring cognitive load.pdf

[27] Tullis TS, Stetson JN. A Comparison of Questionnaires for Assessing Website Usability. [Retrieved 2010 November 23] available from http://www.upassoc.org/usability_resources/confe rence/2004/UPA-2004-TullisStetson.pdf

(C) James et al.; Licensee Bentham Open.

This is an open access article licensed under the terms of the Creative Commons Attribution Non-Commercial License (http: //creativecommons.org/licenses/ by-nc/3.0/) which permits unrestricted, non-commercial use, distribution and reproduction in any medium, provided the work is properly cited. 